\title{
Phosphorylated and Cross-Linked Wheat Starches in the Presence of Polyethylene Oxide and Their Application in Biocomposite Films
}

\author{
Graziella Pinheiro Bruni, Jean Paulo de Oliveira, Shanise Lisie Mello El Halal, \\ Wladimir Hernadez Flores, Andre Gundel, Martha Zavariz de Miranda, \\ Alvaro Renato Guerra Dias, and Elessandra da Rosa Zavareze*
}

Wheat starch is modified by phosphorylation and cross-linking. Starches are evaluated for phosphorus content, amylose content, swelling power, solubility, pasting properties, crystallinity, and morphology. Films are made with phosphorylated and cross-linked starches, and with addition of $10 \%(w / w)$ polyethylene oxide (PEO). The films are evaluated for morphology, water vapor permeability, mechanical properties, crystallinity, roughness, and angle of contact with water. Phosphorylated starch shows higher phosphorus content, amylose content, swelling power, and solubility than cross-linked starch and native starch did. The starch film containing PEO presents discontinuous morphology, is more crystalline and rugged, and less hydrophilic than starch films without PEO. The biocomposite proves promising for usage in flexible packaging.

\section{Introduction}

Wheat starch can be used to produce biodegradable films because of its low cost, and renewable and biodegradable properties. However, use of natural starch films is limited due to their poor mechanical properties and low water barrier. To improve these properties, the association of natural and synthetic polymers for biocomposite formation has been studied. Previous studies showed that composite films made from starch and polyvinyl alcohol (PVA) ${ }^{[1]}$ and polyvinyl chloride $(\mathrm{PVC})^{[2]}$ exhibit good processing characteristics, and improved mechanical and water barrier properties. The mixture

G. P. Bruni, J. P. de Oliveira, Dr. S. L. M. El Halal, Prof. A. R. G. Dias, Prof. E. da Rosa Zavareze

Departamento de Ciência e Tecnologia Agrindustrial

Universidade Federal de Pelotas

Pelotas, 96010-900 RS, Brazil

E-mail: elessandrad@yahoo.com.br

Prof. W. H. Flores, Prof. A. Gundel

Universidade Federal do Pampa

Bagé, 96413-172 RS, Brazil

Dr. M. Z. de Miranda

Empresa Brasileira de Pesquisa Agropecuária - Centro Nacional de Pesquisa de Trigo

Passo Fundo, 99050-970 RS, Brazi

DOI: 10.1002/star.201700192 of starch with polyethylene oxide (PEO) to produce biocomposite films is interesting because PEO is biodegradable, biocompatible, and forms hydrogen bonds with oxygen, which allows intermolecular interactions with the components of the polymer matrix. Furthermore, the presence of PEO improves the poor mechanical properties of films produced with starch and provides a semi-crystalline structure to the final material, which is an attractive property of films. ${ }^{[3]}$ Furthermore, the interaction between starch and PEO is influenced by the origin and proportion of starch and by the $\mathrm{PEO}$ semi-crystalline structure. ${ }^{[3]}$

Modified starches, such as phosphorylated and cross-linked starches, have been suggested for use in films due to their excellent mechanical and water barrier properties compared to native starch films. Phosphorylation is a chemical modification in which phosphate groups are introduced into starch. The negatively charged phosphate groups cause repulsion among the starch chains and, consequently, increase their hydration. Thus, phosphorylation decreases the starch gelatinization temperature and increases retrogradation. Other changes in starch properties include increase in swelling power, granule solubilization, paste clarity, and starch gel viscosity. ${ }^{[4]}$ These properties are advantageous in the development of biodegradable films, as well as in improving film characteristics.

Cross-linking is a chemical modification obtained using reagents such as trimetaphosphate, sodium tripolyphos phate, epichlorohydrin, phosphoryl chloride, and a mixture of adipic acid, acetic anhydride, and vinyl chloride, all capable of forming intra- and intermolecular bonds between the hydroxyl groups of starch. ${ }^{[5]}$ Biodegradable starch films prepared from cross-linked starches provide improved mechanical properties, abrasion/cut through, resistance to stress cracking, high-temperature mechanical properties, overload characteristics, and decreased inflexibility. ${ }^{[6]}$ However, the degree of improvement depends on the type and content of cross-linking agent. Besides, the structure and molecular weight of the starch also affects the intermolecular interactions between molecules. 
Jagadish and Raj ${ }^{[7]}$ prepared films from blends of starch and PEO, and reported that these films presented interesting characteristics for application in food packaging. These authors observed that films with higher $\mathrm{PEO} /$ starch ratios presented higher tensile strength and lower water-vapor transmission rate. However, the behavior of films made with modified starch and PEO was not studied. The use of starches modified by phosphorylation or cross-linking may facilitate the interaction between starch and PEO. Therefore, the objective of this study was to develop and characterize biocomposite films using phosphorylated and cross-linked wheat starches and PEO in order to obtain materials with improved properties.

\section{Experimental Section}

\subsection{Materials}

Wheat (Triticum aestivum) grains of BRS Parrudo cultivar were provided by Embrapa-Trigo (State of Rio Grande do Sul, Brazil). All the chemical reagents used were of analytical grade.

\subsection{Isolation of Starch}

Wheat starch was extracted according to the procedure suggested by Knight and Olson. ${ }^{[8]}$ Briefly, a mixture of wheat flour and water was prepared in a ratio of 2:1 (w.v). After the formed mass was washed with water until complete removal of the starch, the starch-water mixture was filtered through a 200-mesh sieve. The filtrate was centrifuged at $3500 \mathrm{rpm}$ for $20 \mathrm{~min}$. After centrifugation, the dark layer on top of the precipitated material was removed and the remainder of the decantate was resuspended in distilled water and centrifuged again. The process was repeated three times. The starch was dried at $40^{\circ} \mathrm{C}$ for $16 \mathrm{~h}$ to approximately $9 \%$ moisture content and stored at $17 \pm 2{ }^{\circ} \mathrm{C}$. The wheat starch presented approximately $89.5 \%$ purity $(0.48 \%$ protein, $0.50 \%$ lipids, and $0.18 \%$ ash). The extraction rate of the wheat starch was approximately $50 \%$.

\subsection{Preparation of Phosphorylated Starch}

Phosphorylation was performed according to the method described by Paschall. ${ }^{[9]}$ Briefly, $167 \mathrm{~mL}$ of $7.54 \%$ (w/v) sodium tripolyphosphate in water was adjusted to $\mathrm{pH} 5.5$ using $1 \mathrm{~mol} \mathrm{~L}^{-1} \mathrm{HCl}$ solution). This solution was mixed with $100 \mathrm{~g}$ (dry basis) of starch and stirred in a magnetic stirrer for 20 min. Then, the mixture was filtered using a vacuum pump (SOLAB, SL-61, Brazil), and the sediment was dried in a forced-air oven for $48 \mathrm{~h}$ at $45^{\circ} \mathrm{C}$. The dried sample was ground in an analytical mill and transferred to an oven with forced-air circulation at $65^{\circ} \mathrm{C}$ for $90 \mathrm{~min}$. Then, the solid was transferred to a stationary oven at $155^{\circ} \mathrm{C}$ for $40 \mathrm{~min}$. After cooling, $300 \mathrm{~mL}$ of $50 \%$ ethanol was added, and the samples centrifuged at $2200 \mathrm{rpm}$ for $5 \mathrm{~min}$. The supernatant was discarded and the resultant material was dried in a forced-air oven at $45^{\circ} \mathrm{C}$ for $24 \mathrm{~h}$. After phosphorylation, the samples were dialyzed to remove unbound phosphorous salts. A suspension of $10 \%(\mathrm{w} / \mathrm{v})$ phosphorylated starch was placed into a $30-\mathrm{cm}$ long cellulose dialysis membrane (12000-16000 molecular weight cut-off, $25 \mathrm{~A}$ porosity) and immersed in distilled water (changed twice a day) under cooling over a period of 3 days. After dialysis, the starch was dried in a forced-air oven at $45^{\circ} \mathrm{C}$ for $24 \mathrm{~h}$. The degree of substitution (DS) was calculated according to Eq. (1).

$$
D S=\frac{163 P}{(3100-124 P)}
$$

where $P$ is the phosphorus content.

\subsection{Preparation of Cross-Linked Starch}

Starch crosslinking was carried out according to the method suggested by Woo and Seib. ${ }^{[10]}$ Briefly, a mixture of $100 \mathrm{~g}$ of starch, $2 \mathrm{~g}$ of sodium trimetaphosphate, and $2 \mathrm{~g}$ sodium sulphate in $200 \mathrm{~mL}$ of distilled water was adjusted to $\mathrm{pH} 11 \mathrm{using} 0.5 \mathrm{~mol} . \mathrm{L}^{-1}$ $\mathrm{NaOH}$ and, then, heated at $35^{\circ} \mathrm{C}$ while stirring (IKA, RW20, Germany) for $16 \mathrm{~h}$. After this period, the mixture was washed with excess distilled water and filtered using a vacuum pump (SOLAB, SL-61, Brazil) before further drying at $40^{\circ} \mathrm{C}$ in an oven with air circulation for $24 \mathrm{~h}$. After modification, the samples were dialyzed to remove unbound phosphate salts. Precisely, a suspension of $10 \%(\mathrm{w} / \mathrm{v})$ cross-linked starch was placed into a 30-cm long cellulose dialysis membrane and immersed in distilled water (changed twice a day) under cooling over a period of 3 days. After dialysis, the starch was dried in a forced-air oven at $45^{\circ} \mathrm{C}$ for $24 \mathrm{~h}$. The DS was calculated according to Eq. (2).

$$
D S=\frac{324 P}{(3100-96 P)}
$$

Where $P$ is the phosphorus content.

\subsection{Characterization of the Modified Starches}

The phosphorus content of the starches was determined according to the method suggested by Smith and Caruso. ${ }^{[1]}$ Briefly, $10 \mathrm{~mL}$ of $10 \%$ zinc acetate was uniformly added to $5 \mathrm{~g}$ of starch samples and completely evaporated on a heating plate. The samples were placed in a muffle at $550{ }^{\circ} \mathrm{C}$ for $2 \mathrm{~h}$. Then, $0.75 \mathrm{~mL}$ of $29 \%$ nitric acid was added and evaporated, and the sample was placed in a muffle at $550^{\circ} \mathrm{C}$ for $30 \mathrm{~min}$. After the sides of the crucible used to dry the samples were washed with $2.5 \mathrm{~mL}$ of $29 \%$ nitric acid and $3.75 \mathrm{~mL}$ of water, the crucible was heated on a water bath for $10 \mathrm{~min}$. The content of the crucible was filtered using four 2.5-mL portions of distilled water. Absorbance at $460 \mathrm{~nm}$ was read using a spectrophotometer after $10 \mathrm{~min}$. A standard curve was created using $0.439 \mathrm{~g}$ of anhydrous monobasic potassium phosphate dissolved $1 \mathrm{~L}$ of distilled water.

Apparent amylose content in starches was determined using the colorimetric method based on iodine as described by McGrance, Cornell, and Rix ${ }^{[12]}$ in which a standard amylose curve was created using pure potato amylose (Sigma-Aldrich).

The swelling power and solubility of the starches at $90^{\circ} \mathrm{C}$ were determined following the method described by Leach, 
McCowen, and Schoch ${ }^{[13]}$ Briefly, $1.0 \mathrm{~g}$ of starch was mixed with $50 \mathrm{~mL}$ of distilled water in centrifuge tubes. The various suspensions were heated at $90^{\circ} \mathrm{C}$ for $30 \mathrm{~min}$. The solubility was expressed as the percentage of undissolved dried solid weight over the initial weight of the dry sample. The swelling power was calculated as the ratio of the weight of the wet sediment to the initial weight of the sample (deducting the amount of soluble starch).

The pasting properties of the starch were determined using a Rapid Visco Analyzer (RVA-4, Newport Scientific, Australia) and the Standard Analysis 1 profile. Viscosity was expressed in rapid visco units (RVU). Starch ( $3.0 \mathrm{~g}$ of $14 \mathrm{~g} / 100 \mathrm{~g}$ wet basis) was weighed directly in a RVA canister and added $25 \mathrm{~mL}$ of distilled water. Parameters comprising pasting temperature, peak viscosity, breakdown, final viscosity, and setback were recorded.

X-ray diffractograms of the starches were obtained using an X-ray diffractometer (XRD-6000, Shimadzu, Brazil). The scanning region of the diffraction ranged between $5^{\circ}$ and $45^{\circ}$, with a target voltage of $30 \mathrm{kV}$, a current of $30 \mathrm{~mA}$, and a scan speed of $1^{\circ} \mathrm{min}^{-1}$. The relative crystallinity (RC) of the starch granules was calculated as described by Rabek ${ }^{[14]}$ according to Eq. (3).

$\mathrm{RC}=\frac{A c}{(A c+A a)} \times 100$

where $A c$ is the crystalline area and $A a$ is the amorphous area on the X-ray diffractograms.

\subsection{Elaboration of Biocomposite Films}

Biocomposite films were prepared using a casting technique. Preliminary tests were performed to define the PEO concentration in the films. For film preparation, a solution was prepared with $3 \%$ starch in $100 \mathrm{~g}$ of distilled water, $0.30 \mathrm{~g}$ glycerol/g dry starch, and 0 or $10 \mathrm{~g}$ of PEO/100 g dry starch. PEO control film was prepared using $3 \%$ PEO in $100 \mathrm{~g}$ of distilled water. The PEO was suspended in water with subsequent stirring in an Ultraturrax homogenizer (IKA, T18B, Werke, Germany) at $11,000 \mathrm{rpm}$ for $5 \mathrm{~min}$; then, starch and glycerol were added. The solution was heated at $90^{\circ} \mathrm{C}$ for $30 \mathrm{~min}$. Then, $20 \mathrm{~g}$ of each film solution was spread on 9-cm diameter acrylic plates and dried in an oven with air circulation at $35^{\circ} \mathrm{C}$ for $16 \mathrm{~h}$. The film samples were stored in a hermetic container at $16^{\circ} \mathrm{C}$ and approximately $65 \%$ relative humidity $(\mathrm{RH})$ using a saturated solution of ammonium nitrate $\left(\mathrm{NH}_{4} \mathrm{NO}_{3}\right)$ for 7 days.

\subsection{Characterization of Biocomposite Films}

\subsubsection{Morphology}

The surface and cross-section morphology of the composites were visualized using a scanning electron microscope (JEOL, JSM-6610LV, New Jersey, USA) with accelerating voltage of $10 \mathrm{kV}$. For cross-sections, the samples were fractured under liquid nitrogen prior to visualization. Samples were then placed in a stub, coated with gold using a sputter Desk V (JEOL, New Jersey, USA), and examined at $300 \times$ magnification.

\subsubsection{Water Vapor Permeability (WVP) of the Biocomposite Films}

Water vapor permeability tests of the films were performed following the American Society for Testing and Materials (ASTM) E96-95 standard method. ${ }^{[15]}$ Each sample was placed and sealed onto the circular opening of a permeation cell containing anhydrous calcium chloride $(0 \% \mathrm{RH})$. Then, the cells were conditioned in desiccators with a saturated sodium chloride solution $(75 \% \mathrm{RH})$ at $25^{\circ} \mathrm{C}$ until the samples reached steadystate conditions. Finally, the cell weight was measured after $48 \mathrm{~h}$.

\subsubsection{Thickness and Mechanical Properties}

The thickness of films was determined using a micrometer to the nearest $0.001 \mathrm{~mm}$, at 8 random positions around the film. Average deposition rates were used in the calculations. The tensile strength and percentage of elongation at the break-up point of the films were evaluated according to the tensile test based on the ASTM D-882-91 method $^{[15]}$ using a Texture Analyzer (TA.XT plus, Stable Micro Systems).

\subsubsection{X-Ray Diffraction}

The film samples were cut into circular pieces, placed in a sample holder, and evaluated using an X-ray diffractometer at a scan range of $5-60^{\circ}(2 \theta), 30 \mathrm{kV}$ voltage, and $30 \mathrm{~mA}$ current.

\subsubsection{Atomic Force Microscopy}

The surface topography of the films was obtained using an atomic force microscope (Agilent Technologies 5500 Equipment, Chandler, AZ, USA) equipped with a commercial, non-contact silicon tip PPPNCL. The cantilever oscillation had a curvature in the nanometre order and resonance frequency of $154 \mathrm{kHz}$. The topography images were analyzed using the Pico Image Basic software. The quantitative parameter of surface roughness (Rq) was calculated using the topographic data extracted from the micrographs.

\subsubsection{Biocomposite Films Contact Angle With Water}

The contact angle of the films with water was determined using a goniometer (Labometric, LB-DX) at room temperature. The samples were adhered to a glass slide using a double-sided tape. A drop $(3 \mu \mathrm{L})$ of water was dripped on the sample surface with a micropipette, and the drop image was captured using a digital camera. The contact angle values were calculated using the ImageJ software using a drop analysis plugin. The values represent the average of five repetition angles.

\subsection{Statistical Analysis}

All analytical determinations were performed in triplicate and the results were submitted to analysis of variance (ANOVA). The 
mean values were compared by Tukey's test or $t$-test with $5 \%$ level of significance.

\section{Results and Discussion}

\subsection{Phosphorus Content of Starches}

The phosphorus content of native starch derives from phospholipids. $^{[15]}$ Our phosphorylated starch showed higher phosphorus content than other starches did (Table 1), indicating that phosphate groups were successfully introduced in the starch chain. Stahl et al., ${ }^{[16]}$ who studied the phosphorylation of corn and pinhão starches, reported lower phosphorus values $(0.25 \%)$ than we did $(0.57 \%)$. However, these authors performed a 7-day long dialysis process, which probably decreased the phosphorous content in their samples, whereas the dialysis carried out in this study was 3-day long.

According to the Food and Drug Administration, starches modified for food use must have a residual phosphorus content of $0.5 \%$ for phosphorylated starch and $0.04 \%$ for cross-linked starch (Table 1). ${ }^{[17]}$ Therefore, phosphorylated corn and pinhão starches could not be used in the food industry. However, they could be employed in the paper industry for sealing pores, and in the textile industry for sizing yarns, as well as in other fields such as production of biodegradable films for flexible packaging.

Deetae et al. ${ }^{[6]}$ evaluated rice starch cross-linked with $1 \%$ sodium trimetaphosphate at $120^{\circ} \mathrm{C}$, with reaction times ranging from 0 to $120 \mathrm{~min}$. These authors reported that the phosphorus content of the starches ranged from 0.007 to $0.030 \%$ according to increasing reaction time.

Liu et al. ${ }^{[18]}$ reported that variations in the phosphorus content of starches can be explained by differences in the distribution of the phosphate groups between amylose and amylopectin. In addition, reaction conditions and starch origin also influence the introduction of phosphate groups in the starch molecule. Starch

Table 1. Phosphorus content, amylose, swelling power, solubility, and pasting properties of the native and modified starches.

\begin{tabular}{lccc}
\hline & \multicolumn{3}{c}{ Starches } \\
\cline { 2 - 4 } Parameters $^{\mathrm{a}}$ & Native & Phosphorylated & Cross-linked \\
\hline Phosphorus content (\%) & $0.06^{\mathrm{c}}$ & $0.57^{\mathrm{a}}$ & $0.09^{\mathrm{b}}$ \\
Degree of substitution & - & $0.030^{\mathrm{a}}$ & $0.009^{\mathrm{b}}$ \\
Apparent amylose content (\%) & $24.75^{\mathrm{b}}$ & $27.65^{\mathrm{a}}$ & $13.02^{\mathrm{c}}$ \\
Swelling power (g/g) & $12.12^{\mathrm{b}}$ & $14.34 \mathrm{a}$ & $6.66^{\mathrm{c}}$ \\
Solubility (\%) & $6.39^{\mathrm{b}}$ & $10.10 \mathrm{a}$ & $2.72^{\mathrm{c}}$ \\
Pasting temperature ( $\left.{ }^{\circ} \mathrm{C}\right)$ & $79.47^{\mathrm{c}}$ & $55.63^{\mathrm{b}}$ & $88.05 \mathrm{a}$ \\
Peak viscosity (RVU) & $235.37 \mathrm{a}$ & $184.5^{\mathrm{b}}$ & $11.41^{\mathrm{c}}$ \\
Breakdown (RVU) & $54.79 \mathrm{a}$ & $28.86^{\mathrm{b}}$ & $3.08^{\mathrm{c}}$ \\
Final viscosity (RVU) & $271.87 \mathrm{a}$ & $218.25^{\mathrm{b}}$ & $12.37^{\mathrm{c}}$ \\
Setback (RVU) & $89.54 \mathrm{a}$ & $62.08^{\mathrm{b}}$ & $4.41^{\mathrm{c}}$ \\
\hline
\end{tabular}

Values with different letters in the same row are significantly different $(p<0.05)$ by a Tukey test. contains two types of hydroxyl groups, primary $(6-\mathrm{OH})$ and secondary $(2-\mathrm{OH}$ and $3-\mathrm{OH})$. These hydroxyl groups react with multifunctional reagents resulting in cross-linked starches. Higher phosphorus content of starch suggests a greater interaction among the polymer chains, which causes the structure to become increasingly rigid.

\subsection{Amylose Content, Swelling Power, and Solubility of Starches}

Interestingly, the phosphorylation process increased the amylose content (Table 1), which could be attributed to the depolymerisation of the external amylopectin chains that can form complexes with iodine. The ability of amylose to produce films has been long known and it is attributed to the ability of its linear chains to interact with other molecules through hydrogen bonds to a higher extent than the branched amylopectin chains. Moreover, amylopectin films are frail because of the high degree of entanglement caused by extensive branching and short average chain length. ${ }^{[19]}$

Phosphorylation increased the swelling power and solubility of starch (Table 1). Sthal et al. ${ }^{[16]}$ reported on the increase of the swelling power of corn and pinhão starches phosphorylated with sodium tripolyphosphate. These authors attributed this result to
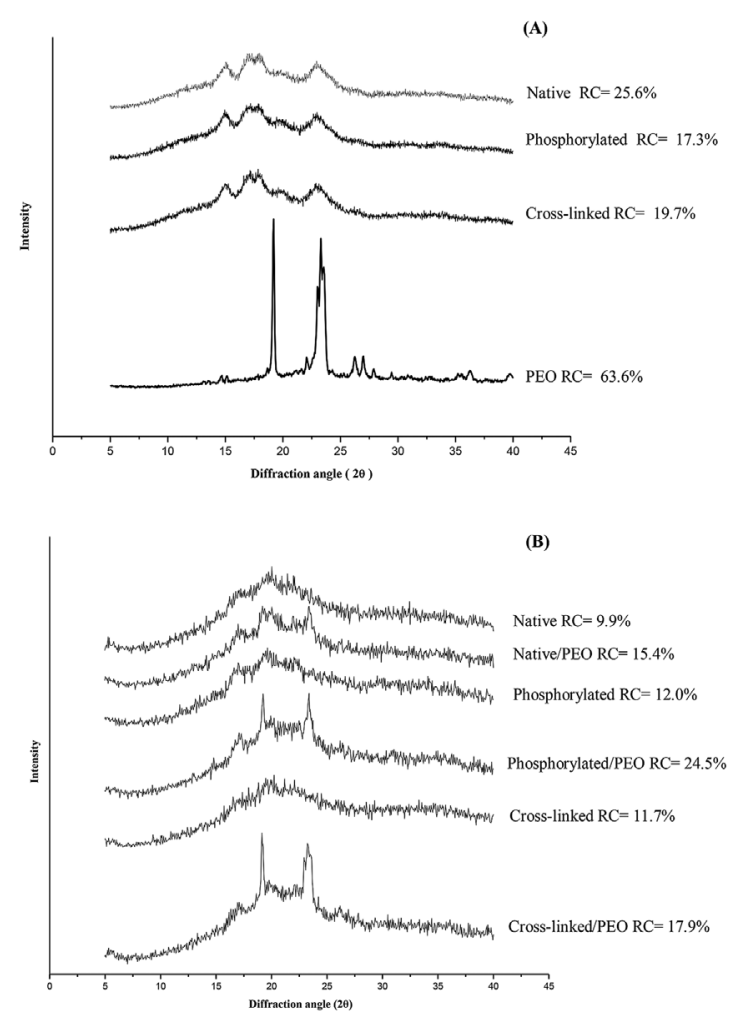

Figure 1. X-ray diffraction patterns and relative crystallinity of native, phosphorylated, and cross-linked wheat starches and polyethylene oxide (PEO) (A), and of films made of native starch, native starch and PEO, phosphorylated starch, phosphorylated starch and PEO, cross-linked starch, and cross-linked starch and PEO (B). 


\section{ADVANCED

the presence of negatively charged phosphate groups in the starch, which reduce the intermolecular binding forces favoring water absorption. However, reduced swelling power of crosslinked starches was observed compared to the native counterparts.

Cross-linking confers the granules a rigid macromolecular structure, which strengthen hydrogen bonds, slows water absorption speed, and increases the resistance of swollen granules to break-up. The increased solubility of phosphorylated starches can be attributed to the introduction of negatively charged phosphate groups in the starch chain, which reduces the strength of bonds in the starch structure. ${ }^{[20]}$

As observed in other studies, ${ }^{[21]}$ modification by cross-linking decreases the solubility of starch in water (Table 1) because crosslinks strengthen the granular structure.

\subsection{Pasting Properties of Starches}

Phosphorylated and cross-linked starches showed reduced peak viscosity, breakdown, final viscosity, and retrogradation (Table 1) compared to native starch. Starches modified by cross-linking showed higher retrogradation than native and phosphorylated starches. Setback, that is, high-viscosity gelled starch, has a great importance in the application of starch paste. During cooling, straight-chain solubilized amylose starch molecules begin to realign and form a stable gel structure. This phenomenon is called retrogradation. ${ }^{[22]}$ The low amylose content in cross-linked starch compared to other starches may be responsible for their low retrogradation.

Cross-linking and phosphorylation confer high and low pasting temperature, respectively, compared to that of native starch. The decrease in the phosphorylated starch pasting

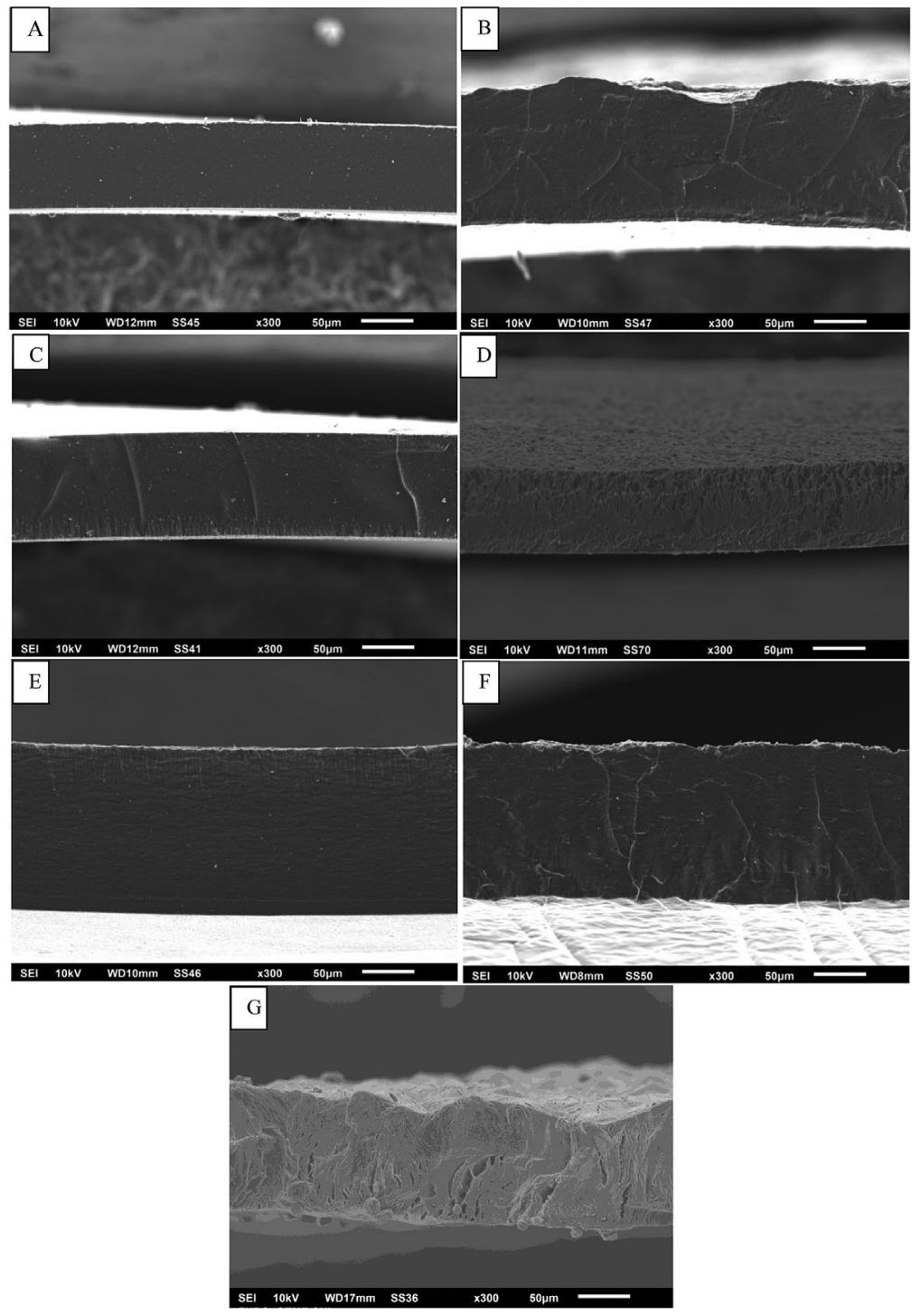

Figure 2. Scanning electron microscopy of the cross section of films made of native starch (A), native starch and polyethylene oxide (PEO) (B), phosphorylated starch (C), phosphorylated starch and PEO (D), cross-linked starch (E), cross-linked starch and PEO (F), and PEO film (G). 
temperature is attributed to the incorporation of negatively charged functional groups (i.e., phosphates) in the starch structure, which reduces the attractive forces in the amorphous region, thereby weakening the intramolecular hydrogen bonding bead and forming binders at low temperatures. ${ }^{[5]}$

The increased pasting temperature of starch after the introduction of cross-links is likely due to the reduced mobility of the amorphous chains in the starch granules resulting from intermolecular bonds. In fact, cross-links enhance the integrity of the starch granules and retard the breakdown of hydrogen bonds during the gelatinization process, thus leading to low viscosity.

\subsection{X-Ray Diffraction of Starches}

The X-rays diffraction patterns of native starches showed peaks at $15^{\circ}, 17^{\circ}, 18^{\circ}$, and $23^{\circ}(2 \theta)$ (Figure 1a), characteristic of cereal starch type A. The chemically modified starches did not show changes in the diffraction patterns (Figure 1). The phosphorylated and cross-linked starches showed reduced crystallinity compared to the native starch (Figure 1a). Błaszczak et al. ${ }^{[23]}$ reported that the phosphorylated waxy cornstarch showed noticeable reduction in crystallinity compared to the native starch. These authors suggested that functional groups were monosubstituted by phosphate mainly in the amorphous regions of the waxy maize structure. Kittipongpatana and Kittipongpatana ${ }^{[24]}$ reported that cross-linking by sodium trimetaphosphate did not alter the pattern of the elephant foot starch X-ray because modifications occurred in the amorphous region of the starch granule.

\subsection{Morphology of Films}

The micrographs of the cross section of the biocomposite films of native and modified starches, with and without the addition of PEO, are shown in Figure 2. The phosphorylated starch film obtained showed cracks (Figure 2C), whereas cross-linked starch films were homogeneous (Figure 2E).
The addition of PEO in the films caused discontinuous cross sections, regardless of the type of starch (Figure 2). Pereira et al. ${ }^{[25]}$ found that blends of PEO and cassava starch were irregular, which was attributed to the characteristic spherulitic structure of PEO. The discontinuities of the biocomposite films affect their properties.

\subsection{WVP of the Films}

The WVP of biocomposite films is shown in Table 2. WVP is an essential parameter for the evaluation of possible biocomposite films applications. The addition of PEO in the cross-linked starch film decreased the WVP (Table 2), which could be related to the high crystallinity of this starch (Figure 1). As previously reported in a study on composite films of chitosan and cellulose, low WVP provides high retention capacity, low water absorption, and adsorption capacity. ${ }^{[26]}$ Alterations in the starch chains following cross-linking reduced water retention compared to native starches, which contributed to reducing the WVP of the film.

The films made from native and phosphate starches, with and without PEO, showed low WVP values, demonstrating that the presence of PEO does not affect this parameter (Table 2). According to Su and Shen, ${ }^{[27]}$ since PEO itself has the ability to retain water, it contributes to the retention of water absorbed by biocomposite films made of native and phosphorylated starches, which are weaker than cross-linked starches.

\subsection{Thickness and Mechanical Properties of Films}

The films made of phosphorylated and cross-linked starches showed increased thickness upon addition of PEO. The phosphorylated starch film without PEO showed higher tensile strength than other films, which was unaltered by the addition of PEO. The higher tensile strength of the phosphorylated starch film could be attributed to its high amylose content compared to that of other starches (Table 1). In fact, most starches with high amylose content confer an elevated tensile strength to the films due to retrogradation.

Table 2. Water vapor permeability, thickness, mechanical properties, and contact angle of films.

\begin{tabular}{|c|c|c|c|c|c|c|}
\hline \multicolumn{2}{|c|}{ Biocomposite $^{a}$} & \multirow[b]{2}{*}{ WVP (g.mm/kPa.day. $\mathrm{m}^{2}$ ) } & \multirow[b]{2}{*}{ Thickness (mm) } & \multirow[b]{2}{*}{ Tensile strength (MPa) } & \multirow[b]{2}{*}{ Elongation (\%) } & \multirow[b]{2}{*}{ Contact angle $\left({ }^{\circ}\right)$} \\
\hline Starch & $\overline{\text { PEO (\%) }}$ & & & & & \\
\hline \multirow[t]{2}{*}{ Native } & 0 & $2.4 \pm 0.1^{\mathrm{b} \mathrm{ns}}$ & $0.131 \pm 0.01^{a}$ & $1.2 \pm 0.2^{b}$ & $53.7 \pm 1.3^{b}$ & $23.8 \pm 0.6^{c}$ \\
\hline & 10 & $2.6 \pm 0.1^{c}$ & $0.120 \pm 0.01^{b}$ & $1.6 \pm 0.1^{\mathrm{c}}$ & $113.4 \pm 0.8^{b}$ & $69.3 \pm 0.1^{\mathrm{a}}$ \\
\hline \multirow[t]{2}{*}{ Phosphorylated } & 0 & $3.2 \pm 0.5^{\mathrm{b} \mathrm{ns}}$ & $0.105 \pm 0.02^{b}$ & $6.5 \pm 0.2^{\mathrm{ans}}$ & $74.8 \pm 4.5^{\mathrm{ans}}$ & $25.35 \pm 0.6^{b}$ \\
\hline & 10 & $2.6 \pm 0.1^{c}$ & $0.116 \pm 0.02^{b}$ & $6.5 \pm 0.2^{\mathrm{a}}$ & $77.1 \pm 2.8^{c}$ & $57.7 \pm 0.1^{c}$ \\
\hline \multirow[t]{2}{*}{ Crosslinked } & 0 & $5.4 \pm 0.4^{\mathrm{a}}$ & $0.131 \pm 0.010^{\mathrm{a}}$ & $1.2 \pm 0.1^{b}$ & $43.8 \pm 2.9^{c}$ & $27.7 \pm 0.2^{\mathrm{a}}$ \\
\hline & 10 & $4.2 \pm 0.1^{\mathrm{a}}$ & $0.170 \pm 0.02^{\mathrm{a}}$ & $2.9 \pm 0.3^{b}$ & $146.0 \pm 0.7^{\mathrm{a}}$ & $66.4 \pm 0.3^{b}$ \\
\hline Film of PEO ${ }^{b}$ & & $6.0 \pm 0.3$ & $0.124 \pm 0.010$ & $2.8 \pm 0.1$ & $165.1 \pm 4.2$ & $40.7 \pm 0.7$ \\
\hline
\end{tabular}

The results are mean \pm standard deviation of three determinations.

Film prepared with only $3 \mathrm{~g}$ of PEO.

Values with different letters in the same column represent significant difference by Tukey test $(p \leq 0.05)$.

${ }^{\text {ns }}$ Significant and insignificant, respectively, by $t$-test $(p \leq 0.05)$, between films with 0 and $10 \%$ PEO. PEO: polyethylene oxide. 


\section{ADVANCED

Addition of PEO increased the tensile strength of the crosslinked starch film, which could be attributed to starch and PEO molecules having a large number of hydroxyl groups in their structures that remain associated by intermolecular hydrogen bonds. Das et al. ${ }^{[28]}$ studied biocomposite films made of crosslinked starch and PVA. These authors reported that the crosslinking agents used to modify the native starch reacted with the $\mathrm{OH}$ groups present in starch and PVA, and formed both linkages contributing to the increased tensile strength of the biocomposites, as well as to reducing water absorption. Moreover, according to Das et al., ${ }^{[28]}$ cross-linking between PVA and starch molecules contributed to the high tensile strength of the crosslinked starch films (Table 2).

The control film containing only PEO showed higher elongation than that of starch films containing PEO (Table 2). Mao et al. ${ }^{[2]}$ reported that the addition of PVA increased the tensile strength and elongation of composite films made of cornstarch. Moreover, these authors reported that the addition of PVA to the starch prevented the development of surface cracks, indicating a good compatibility of starch and PVA. In fact, both the starch and PVA are polar substances harboring hydroxyl groups $(-\mathrm{OH})$, which form intramolecular and intermolecular hydrogen bonds that improve the integrity of starch-PVA mixtures.

Pereira et al. ${ }^{[3]}$ reported that the interaction between starch and PEO in various blends depends on their proportion and, especially, on the type of starch. When the amount of starch in the mixture is low, intra-chain interactions form preferentially. When the amount of starch is increased, intermolecular hydrogen bonds form between the hydroxyl groups of the starch and the PEO oxygen atoms. Therefore, PEO proved capable of forming strong interactions with starches, forming biocomposite films with improved mechanical properties compared to the films with no PEO addition.
(A)

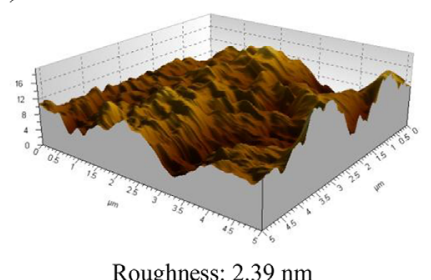

(C)

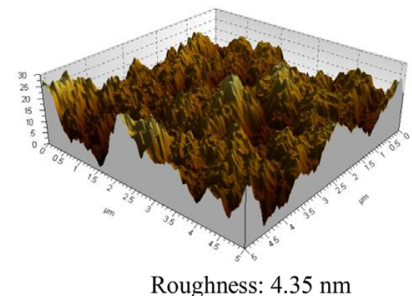

(E)

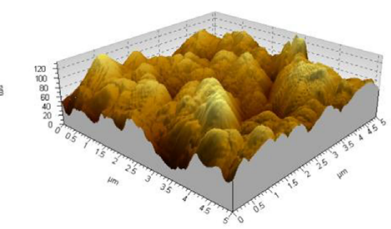

Roughness: $18.3 \mathrm{~nm}$
(B)

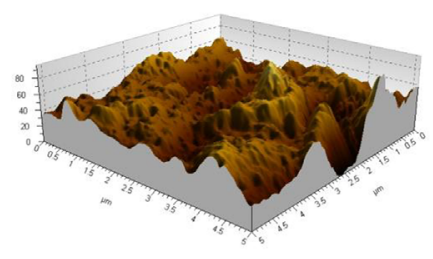

Roughness: $11.2 \mathrm{~nm}$

(D)

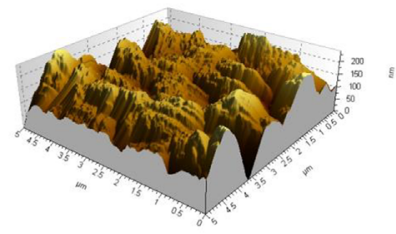

Roughness: $30.2 \mathrm{~nm}$

(F)

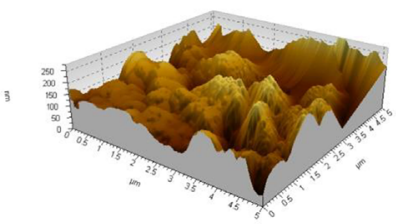

Roughness: $39.5 \mathrm{~nm}$

(G)

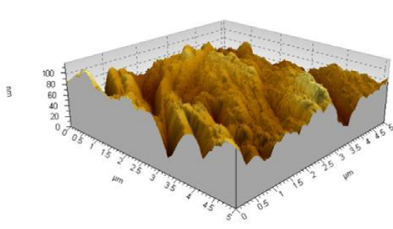

Roughness: $14.7 \mathrm{~nm}$

Figure 3. Atomic force microscopy of films made of native starch (A), native starch and polyethylene oxide (PEO) (B), phosphorylated starch (C), phosphorylated starch and PEO (D), cross-linked starch (E), cross-linked starch and PEO (F), and PEO film (G). 


\subsection{X-Ray Diffraction of Films}

The X-ray diffraction and relative crystallinity of the native, phosphorylated, and cross-linked starches films, with and without PEO, are shown in Figure $1 \mathrm{~b}$. The peaks at $19.2^{\circ}$ and $23.3^{\circ}$ are more intense in the films with PEO compared to the films without PEO. According to Pereira et al., ${ }^{[3]}$ the peak around $19^{\circ}$ is related to the crystallographic plane (120), whereas the peak around $23^{\circ}$ may correspond to the planes: (032), (132), (112), (212), (004), and (124). Furthermore, as shown in Figure 1a, pure PEO has peaks from $16^{\circ}$ to $30^{\circ}$, which are characteristic of crystalline PEO structures. ${ }^{[3]}$

The addition of PEO increased the relative crystallinity of the films due to its high crystallinity (Figure 1a). Moreover, the high crystallinity of PEO contributed to the decrease of the WVP values and to the increase of the tensile strength of cross-linked starch films (Table 2).

\subsection{Atomic Force Microscopy of Films}

The 3D topography of the films is shown in Figure 3. The images indicate structures with irregularities represented by alternating dark and light regions. Roughness values vary for all films, with films with PEO having higher roughness values (Figure 3). Furthermore, the films containing PEO had a rougher surface (Figure 2) than films without PEO did, confirming that the PEO favors the formation of rougher biocomposites. Kaczmarek et al. ${ }^{[30]}$ reported that a film made of pectin and PEO had a high roughness $(54.3 \mathrm{~nm})$ due to the presence of spherulites of different sizes forming layers or "smooth hills" on the polymer surface.

\subsection{Contact Angle of the Films}

The films with added PEO (Figure 4B, D, and F) showed higher contact angle than the films without PEO did (Figure 4A, C, and E, and Table 2). Since higher contact angle indicates lower surface hydrophilicity, the surface of the film with PEO is supposedly less hydrophilic. Jayasekara et al. ${ }^{[31]}$ reported that starch and PVA blends were hydrophobic due to the presence of impurities on their surfaces or due to the three-dimensional helical structure of the polymer matrix.

The films with rough surfaces (Figures 2 and 3 ) also showed high contact angle (Figure 4). According to Jayasekara et al., ${ }^{[31]}$
(A)

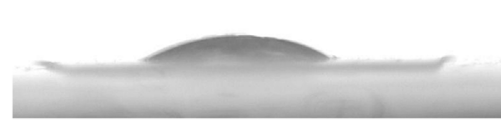

(C)

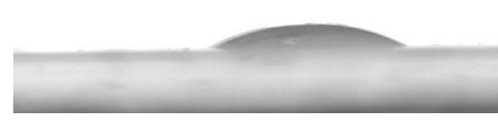

(E)
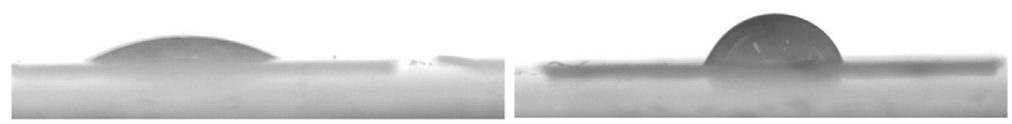

(B)

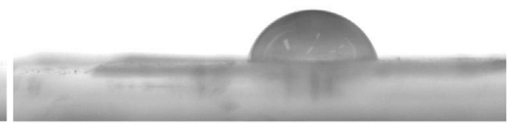

(D)

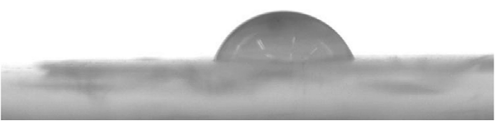

(F)

(G)

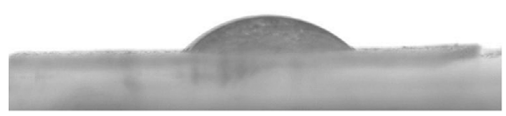

Figure 4. Contact angle of films made of native starch (A), native starch and polyethylene oxide (PEO) (B), phosphorylated starch (C), phosphorylated starch and PEO (D), cross-linked starch (E), cross-linked starch and PEO (F), and PEO film (G). 
roughness is another factor that may be related to the increase of the contact angle. In fact, the contact angle of films increases with the surface roughness. Phosphorylated and cross-linked starches were produced to reduce the hydrophilicity of biocomposite films. As evident highlighted in Figure 4G and Table 2, PEO is less hydrophilic than starch, which is reflected by the contact angle value of pure PEO films. Therefore, the incorporation of PEO also contributed to the reduction of the hydrophilicity of biocomposite films.

\section{Conclusions}

Phosphorylation and cross-linking confer different characteristics to wheat starch. The phosphorylated starch has higher phosphorus content, amylose content, swelling power, and solubility than the cross-linked starch does. The granules of cross-linked starch are resistant to high temperatures due to inter- and intermolecular bonds. In addition, phosphorylated and cross-linked starches show decreased peak viscosity at their breakdown point, final viscosity, retrogradation, and relative crystallinity compared to native starch. Starch film containing PEO presented discontinuous morphology, was more crystalline, more rugged, and less hydrophilic than starch films without PEO did. Therefore, the films with and without PEO possess properties for different industrial applications, especially for flexible packaging. However, future studies are needed to evaluate all the potential applications.

\section{Acknowledgements}

We would like to thank CAPES, Embrapa, CNPq, FAPERGS, SCT-RS, CEME-SUL and Pólo de Inovação Tecnológica em Alimentos da Região Sul.

\section{Conflict of Interest}

The authors declare no conflict of interest.

\section{Keywords}

biocomposites, cross-linking, phosphorylation, polyethylene oxide, wheat starch

Received: July 23, 2017 Revised: December 6, 2017 Published online:
[1] B. Priya, V. K. Gupta, D. Pathania, A. S Singh, Carbohydr. Polym. 2014, 109, 171.

[2] M. I. Ali, S. Ahmed, I. Javed, N. Ali, N. Atiq, A. Hameed, G. Robson, Int. J. Environ. Sci. Technol. 2014, 11, 339.

[3] A. G. B. Pereira, A. T. Paulino, C. V. Nakamura, E. A. Britta, A. F. Rubira, E. C. Muniz, Mater. Sci. Eng.: C 2011, 31, 443.

[4] A. A. Karim, L. C. Toon, V. P. L. Lee, W. Y. Ong, A. Fazilah, T. Noda, J. Food Sci. 2007, 72, 132.

[5] J. Singh, L. Kaur, O. J. McCarthy, Food Hydrocolloids 2007, 21, 1.

[6] P. Deetae, S. Shobsngo, W. Varanyanond, P. Chinachoti, O. Naivikul, S. Varavinit, Carbohydr. Polym. 2008, 73, 351.

[7] R. S. Jagadish, B. Raj, Food Hydrocolloids 2011, 25, 1572.

[8] J. W. Knight, R. M. Olson, Starch: Chemistry and Technology, Academic Press, New York 1984.

[9] E. F. Paschall, Methods in Carbohydrate Chemistry, Whiistler, R. L. (Eds.), Vol. 4, Academic Press, New York 1964, p. 294.

[10] K. Woo, P. A. Seib, Carbohydr. Polym. 1997, 33, 263.

[11] R. J. Smith, J. Caruso, Whistler, R. L. (Ed.), Methods in Carbohydrate Chemistry: Starch, Vol. 4, Academic Press, New York 1964, pp. 42.

[12] S. J. McGrance, H. J. Cornell, C. J. Rix, Starch/Stärke 1998, 50, 158.

[13] H. W. Leach, L. D. McCowen, T. J. Schoch, Cereal Chem. 1959, 36, 534.

[14] J. F. Rabek, Experimental methods in polymer chemistry: applications of wide-angle X-ray diffraction (WAXD) to the study of the structure of polymers, Wiley Interscience, Chichester 1980.

[15] ASTM. (1995). American Society for Testing and Materials. Tensile properties of thin plastic sheeting, in Annual Book of ASTM Standards. ASTM, Philadelphia, p. D 882.

[16] J. A. Stahl, L. P. Lobato, V. C. Bochi, E. H. Kubota, L. C. Gutkoski, T. Emanuelli, LWT-Food Science and Technol. 2007, 40, 1206.

[17] FDA - Food and Drug Administration. http://www.fda.gov/ InternationalPrograms/Agreements/ConfidentialityCommitments/ ucm228083.htm (Accessed Sept 2016).

[18] H. Liu, L. Ramsden, H. Corke, Cereal Chem. 1999, 76, 938.

[19] A. Rindlav-Westling, P. Gatenholm, Biomacromolecules 2003, 4, 166.

[20] M. Z. Sitohy, S. S. El-Saadany, M. F. Ramadan, S. M. Labib, StarchStarke 2000, 52, 101.

[21] S. H. Koo, K. Y. Lee, H. G. Lee, Food Hydrocolloids 2010, 24, 619.

[22] Y. Zhang, K. Zhu, S. He, L. Tan, X. Kong, Food Hydrocolloids 2016, 52, 785.

[23] W. Błaszczak, E. Bidzińska, K. Dyrek, J. Fornal, M. W. E. Michalec, Carbohydr. Polym. 2012, 85, 86.

[24] O. S. Kittipongpatana, N. Kittipongpatana, LWT-Food Science and Technol. 2011, 44, 1766.

[25] A. G. Pereira, R. F. Gouveia, G. M. Carvalho, A. F. Rubira, E. C. Muniz, Mater. Scie. Eng.: C 2009, 29, 499.

[26] M. Phisalaphong, N. Jatupaiboon, Carbohydr. Polym. 2008, 74, 482.

[27] C. C. Su, Y. H. Shen, Coll. Surf. A 2008, 312, 1.

[28] K. Das, D. Ray, N. R. Bandyopadhyay, A. Gupta, S. Sengupta, S. Sahoo, M. Misra, Ind. Eng. Chem. Res. 2010, 49, 2176.

[29] L. J. Mao, S. Imam, S. Gordon, P. Cinelli, E. Chiellini, J. Polym. Environ. 2000, 8, 205.

[30] H. Kaczmarek, K. Bajer, P. Gałka, B. Kotnowska, Polym. Degrad. Stab. 2007, 92, 2058.

[31] R. Jayasekara, I. Harding, I. Bowater, G. B. Y. Christie, G. T. Lonergan, Polym. Test. 2004, 23, 17. 